LETTERS TO THE EDITOR

\title{
Synthesis and Structure of Zinc(II) Complexes with 2,2'-Bipyridine
}

\author{
E. B. Dianov ${ }^{a}$, I. G. Pervova ${ }^{a}$, E. A. Dvoskin ${ }^{a}$, and P. A. Slepukhin ${ }^{b}$ \\ ${ }^{a}$ Ural State Forestry University, Sibirskii trakt 37, Yekaterinburg, 620100 Russia \\ *e-mail:dianova-62@mail.ru \\ ${ }^{b}$ Postovskii Institute of Organic Synthesis, Ural Branch, Russian Academy of Sciences, Yekaterinburg, Russia
}

Received November 2, 2017

\begin{abstract}
The structure of zinc(II) complexes with 2,2'-bipyridine obtained by a direct synthesis from multicomponent mixtures was studied by the method of X-ray structural analysis. The effects of the ligand environment on the composition of $\mathrm{Zn}\left|\mathrm{N}_{x} \mathrm{O}_{y}\right|$ coordination unit and on the nature of resulting polyhedra in the synthesized complex compounds were established.
\end{abstract}

Keywords: heteroligand complexes, zinc complexes, 2,2'-bipyridine, coordination unit composition

DOI: $10.1134 / \mathrm{S} 1070363218040357$

Synthesis, properties, and structure of heteroligand complexes are among actual problems of modern coordination chemistry, which are of essential importance for theoretical substantiating of the behavior of polyfunctional ligands capable of interacting with metal cations in various ways. Competitive interaction between ligands and use of several metals for obtaining complexes can improve practically useful properties of intracomplex compounds that open up new routes in the simulation of chemical processes in multicomponent systems.

Synthesis methods and structural analysis data have been described for the heteroligand zinc-lanthanide complexes with luminescent properties, which can be applied as laser materials, components of luminescent thin films, optical amplifiers, sensors, and radiating layers of electroluminescent devices [1]. The order of reagents addition, for example, addition of 2,2'-bipyridine (bpy) and metal salts, affects the composition and structure of the formed complex: zinc atom coordination number varies from 4 to 5 depending on the bpy molecules coordination, which results in the change of the configuration of atoms surrounding zinc from a tetrahedron to a distorted tetragonal pyramid.

To obtain complex compounds capable of serving as models of fluorescent labels for biological objects, we synthesized zinc complexes using 2,2'-bipyridine and adrenaline. Heteroligand complexes were obtained by the direct synthesis. As a result, 2,2'-bipyridinezinc acetate dihydrate was obtained. Its crystal structure was determined by the X-ray structural analysis (Fig. 1). According to the X-ray data, molecules of the complex in the crystal are arranged in partials position on the second-order axis. The zinc atom is in a distorted octahedral environment consisting of four oxygen atoms belonging to two acetate ions and two water molecules, and of two 2,2'-bipyridine nitrogen

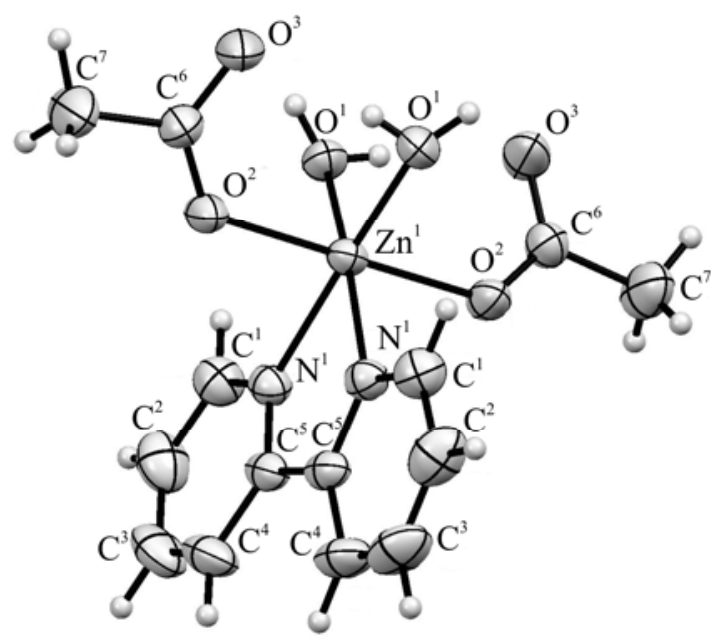

Fig. 1. General view the $\mathrm{Zn}(\mathrm{OAc})_{2}(\mathrm{bpy})\left(\mathrm{H}_{2} \mathrm{O}\right)_{2}$ complex molecule in the crystal. 

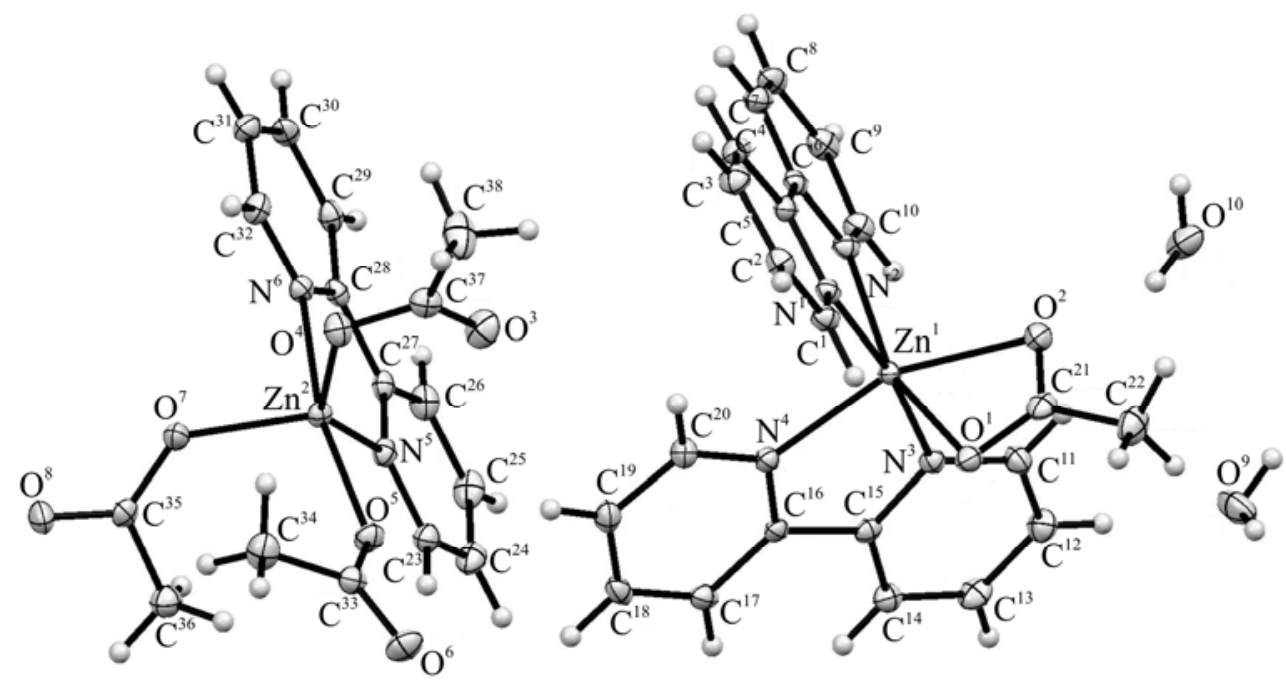

Fig. 2. General view of the $\left[\mathrm{Zn}(\mathrm{OAc})(\mathrm{bpy})_{2}\right]^{+}\left[\mathrm{Zn}(\mathrm{OAc})_{3}(\mathrm{bpy})\right]^{-}\left(\mathrm{H}_{2} \mathrm{O}\right)_{2}$ complex molecule in the crystal.

atoms. 2,2'-Bipyridine is a bidentate ligand, whereas acetate ions and water are monodentate. The molecule conformation is fixed by the intramolecular hydrogen bond between the acetate ion and one of water protons; the second proton is involved in the formation of the intermolecular hydrogen bond with the carbonyl group of the acetate ion of the neighboring molecule.

The resulting complex does not luminesce under UV irradiation.

To obtain biologically compatible model complex compounds [2], the synthesis was fulfilled using aqueous solutions of zinc(II) acetate and adrenaline chloride $\left(c=10^{-3} \mathrm{M}\right)$ and a solution of 2,2'-bipyridine in ethanol $\left(c=5 \times 10^{-5} \mathrm{M}\right)$. The synthesis was carried out at the ratio zinc : adrenaline $:$ bpy $=1: 2: 1$. Hydrated zinc zincate $\left[\mathrm{Zn}(\mathrm{OAc})(\mathrm{bpy})_{2}\right]^{+}\left[\mathrm{Zn}(\mathrm{OAc})_{3}(\mathrm{bpy})\right]^{-}\left(\mathrm{H}_{2} \mathrm{O}\right)_{2}$ was obtained, which contains $2,2^{\prime}$-bipyridine as the

Selected bond lengths in the complex $\left[\mathrm{Zn}(\mathrm{OAc})(\mathrm{bpy})_{2}\right]^{+}$. $\left[\mathrm{Zn}(\mathrm{OAc})_{3}(\mathrm{bpy})\right]^{-}\left(\mathrm{H}_{2} \mathrm{O}\right)_{2}$

\begin{tabular}{c|l||l|l}
\hline Bond & \multicolumn{1}{|c||}{$d, \AA$} & Bond & \multicolumn{1}{c}{$d, \AA$} \\
\hline $\mathrm{Zn}^{1}-\mathrm{N}^{1}$ & $2.1294(16)$ & $\mathrm{Zn}^{2}-\mathrm{N}^{5}$ & $2.1544(17)$ \\
$\mathrm{Zn}^{1}-\mathrm{N}^{2}$ & $2.1120(18)$ & $\mathrm{Zn}^{2}-\mathrm{N}^{6}$ & $2.1596(18)$ \\
$\mathrm{Zn}^{1}-\mathrm{N}^{3}$ & $2.1463(16)$ & $\mathrm{Zn}^{2}-\mathrm{O}^{5}$ & $2.0195(15)$ \\
$\mathrm{Zn}^{1}-\mathrm{N}^{4}$ & $2.1215(16)$ & $\mathrm{Zn}^{2}-\mathrm{O}^{4}$ & $2.0354(14)$ \\
$\mathrm{Zn}^{1}-\mathrm{O}^{1}$ & $2.1785(15)$ & $\mathrm{Zn}^{2}-\mathrm{O}^{7}$ & $2.0183(14)$ \\
$\mathrm{Zn}^{1}-\mathrm{O}^{2}$ & $2.1720(14)$ & $\mathrm{O}^{4}-\mathrm{C}^{37}$ & $1.278(3)$ \\
$\mathrm{Zn}^{1}-\mathrm{C}^{21}$ & $2.513(2)$ & $\mathrm{O}^{3}-\mathrm{C}^{37}$ & $1.231(3)$ \\
\hline
\end{tabular}

only ligand because of the competitive interaction between 2,2'-bipyridine and adrenaline.

According to the X-ray data, the zinc atom in the anion composition has a strongly distorted trigonalbipyramid environment (Fig. 2). Three acetate ions act as classic monodentate ligands and 2,2'-bipyridine - as a bidentate ligand. The bond lengths in the carboxyl fragments of acetate ions are equal, which points to a strong delocalization of their charge within the complex anion (see the table). Zinc atom of the cation part of the complex has a distorted octahedral environment with the bidentate acetate ion, which is $\eta$-coordinated to the zinc atom. The metal-oxygen bond lengths are slightly longer than those in the anionic part at comparable metal-ligand bond lengths for $2,2^{\prime}-$ bipyridine fragments.

Zinc complexes with 2,2'-bipyridine can have coordination number five in a somewhat different coordination, namely with participation of two nitrogen atoms of the 2,2'-bipyridine molecules and of the oxygen atom of one water molecule [3, 4].

The formation of the zinc complex [ $\left.\mathrm{Zn}(\mathrm{OAc})(\mathrm{bpy})_{2}\right]$ was noted previously in other synthesis conditions and with other components. Similar coordination environments of the zinc atom were found in the complexes $\left[\mathrm{Zn}(\mathrm{OAc})(\mathrm{bpy})_{2}\right]_{2}$ (TCNQ) $2 \mathrm{MeOH}$ (TCNQ is tetracianoquinodimethane) [5], $\left[\mathrm{Zn}(\mathrm{bpy})_{2}(\mathrm{OAc})\right]\left(\mathrm{ClO}_{4}\right) \mathrm{H}_{2} \mathrm{O}$ $[6,7]$, and $\left[\mathrm{Zn}(\mathrm{OAc})(\mathrm{bpy})_{2}\right]\left[\mathrm{Mn}(\mathrm{dca})_{3}\left(\mathrm{H}_{2} \mathrm{O}\right)\right]$ (dca is dicyanamide) [8].

Thus, by the synthesis in the competitive conditions we have obtained for the first time zinc(II) hetero- 
ligand complexes with different zinc(II) coordination numbers, composition, and nature of atoms in the nearest coordination environment. The compounds are stable and can be obtained in required quantities in repeated syntheses. The study in this paper expands the list of intracomplex compounds with determined structures.

$\left[\mathrm{Zn}(\mathbf{O A c})_{2}(\mathbf{b p y})\right]\left(\mathbf{H}_{\mathbf{2}} \mathbf{O}\right)_{2}$. Aqueous $10^{-3} \mathrm{M}$ solutions of zinc(II) acetate (analytically-pure grade) and terbium(III) acetate (analytically-pure grade) and a $5 \times 10^{-5} \mathrm{M}$ 2,2'-bipyridine (chemically-pure grade) solution in ethanol were mixed at the ratio zinc : terbium : bpy $=$ $1: 1: 1$. The mixture was kept for 30 min with heating to a temperature of no higher than $30^{\circ} \mathrm{C}$, then left in air for evaporation of the solvent at room temperature and atmospheric pressure.

$\left[\mathrm{Zn}(\mathrm{OAc})(\mathrm{bpy})_{2}\right]^{+}\left[\mathrm{Zn}(\mathrm{OAc})_{3}(\mathrm{bpy})\right]^{-}\left(\mathrm{H}_{2} \mathrm{O}\right)_{2}$. A mixture of $10^{-3} \mathrm{M}$ solutions of zinc(II) acetate and adrenaline chloride and a $5 \times 10^{-5} \mathrm{M} 2,2^{\prime}$-bipyridine solution in ethanol with the ratio zinc : adrenaline : bpy $=$ 1 : 2 : 1 was kept for $60 \mathrm{~min}$ with heating to a temperature of no higher than $30^{\circ} \mathrm{C}$, then left in air for evaporation of the solvent at room temperature and atmospheric pressure.

The X-ray structural analysis of the compound $\mathrm{C}_{14} \mathrm{H}_{18} \mathrm{~N}_{2} \mathrm{O}_{6} \mathrm{Zn}$ was carried out on an Xcalibur 3 automatic diffractometer according to the standard procedure [MoK-radiation, graphite monochromator, $\omega$-scanning in steps of $1^{\circ}$ at 295(2) K]. The structure was solved by the least squares method using the SHELXS program and refined by the SHELXL program [9] in the anisotropic (isotropic for hydrogen atoms) approximation. The main crystallographic parameters and results of the structure refinement: monoclinic crystal, $a$ 15.4642(15), $b$ 12.8170(6), $c$ $8.1739(8) \AA ; \beta 92.708(8)^{\circ}, V 1618.3(2) \AA^{3}$, space group $C 2 / c, Z 4, \mu\left(\mathrm{MoK}_{\alpha}\right) 1,549 \mathrm{~mm}^{-1}$. At the angles $6.36^{\circ}<2 \theta<56.56^{\circ} 5164$ reflections were measured, of them 1995 independent $\left(R_{\text {int }} 0.0190\right)$. $Q$ factor for $F^{2} 1.000, R_{1} 0.0249, w R_{2} 0.0566$ [by reflections with $I>2 \sigma(I)], R_{1} 0.0363, w R_{2} 0.0579$ (by all reflections), $\Delta \rho_{\bar{e}} 0.32 /-0.31 \bar{e} / \AA^{3}$.

The X-ray structural analysis of the compound $\mathrm{C}_{38} \mathrm{H}_{40} \mathrm{~N}_{6} \mathrm{O}_{10} \mathrm{Zn}_{2}$ was carried out on an Xcalibur 3 automatic diffractometer according to the standard procedure [MoK-radiation, graphite monochromator, $\omega$-scanning in steps of $1^{\circ}$ at $\left.108(2) \mathrm{K}\right]$. The structure was solved and refined using the Olex2 software package [10]. The structure was solved using the Superflip program [11] and refined by the least squares method with respect to $F^{2}$ using the ShelXL program [9] in the anisotropic (isotropic for hydrogen atoms) approximation. The main crystallographic parameters and results of the structure refinement: triclinic crystal, $a$ 10.0455(3), $b$ 14.4152(4), c 14.8275(5) $\AA ; \alpha 113.006(3)^{\circ}$, $\beta 100.492(3)^{\circ}, \gamma 96.688(3)^{\circ} ; V 1901.09(11) \AA^{3}$, space group $P-1, Z 2, \mu\left(\mathrm{Mo}_{\alpha}\right) 1.328 \mathrm{~mm}^{-1}$. At angles $3.14^{\circ}<$ $2 \theta<61.82^{\circ} 18351$ reflections were measured, of them 10307 independent $\left(R_{\text {int }} 0.0279\right)$. $Q$ factor for $F^{2} 1,018$, $R_{1} 0.0358, w R_{2} 0.0969$ [by reflections with $I>2 \sigma(I)$ ], $R_{1} 0.0490, w R_{2} 0.1110$ (by all reflections), $\Delta \rho_{\bar{e}} 0.89 /$ $-0.62 \bar{e} / \AA^{3}$.

Crystallographic data are deposited in the Cambridge Crystallographic Data Centre (CCDC, 1575687 1575688).

\section{REFERENCES}

1. Egorov, E.N., Mikhalyova, E.A., Kiskin, M.A., Pavlishchuk, V.V., Sidorov, A.A., and Eremenko, I.L., Russ. Chem. Bull., 2013, vol. 62, no. 10, p. 2141. doi 10.1007/ s11172-013-0313-9

2. Skorik, N.A., Bukholtseva, E.I., and Filippova, M.M., Tomsk State Univ. J. Chem., 2015, no. 2, p. 87. doi 10.17223/24135542/2/9

3. Singh, G., Kapoor, I.P.S., Kumar, D., Singh, U.P., and Goel, N., Inorg. Chim. Acta, 2009, vol. 362, p. 4091. doi 10.1016/j.ica.2009.06.003

4. Liu, M. and Arora, S.K., Acta Cryst., 1993, vol. 49, p. 372 . doi 10.1107/S0108270192009478

5. Hudson, T.A. and Robson, R., Crystal Growth Design, 2009, vol. 9, p. 1658. doi10.1021/cg801400j

6. Chen, X.M. and Xu, Z.T., Polyhedron, 1994, vol. 13, p. 3329. doi 10.1016/s0277-5387(00)83115-0

7. Talaei, Z., Morsali, A., and Mahjoub, A.R., J. Coord. Chem., 2006, vol. 59, p. 643. doi 10.1080/ 00958970500395898

8. Wang, Z.M., Sun, B.W., Luo, J., Gao, S., Liao, C.S., Yan, C.H., and Li, Y., Polyhedron, 2003, vol. 22, no. 3, p. 433. doi 10.1016/S0277-5387(02)01366-9

9. Sheldrick, G.M., Acta Cryst. (A), 2008, vol. 64, no. 1, p. 112. doi 10.1107/S0108767307043930

10. Dolomanov, O.V., Bourhis, L.J., Gildea, R.J., Howard, J.A.K., and Puschmann, H., J. Appl. Cryst., 2009, vol. 42, p. 339. doi 10.1107/S0021889808042726

11. Palatinus, L. and Chapuis, G., J. Appl. Cryst., 2007, vol. 40, p. 786. doi 10.1107/S0021889807029238 